\section{Initial public offerings, 4th quarter 1998}

The fourth quarter saw four IPOs raising a total of $\$ 93.7$ million. Value raised in US\$ millions. Source: BioCentury
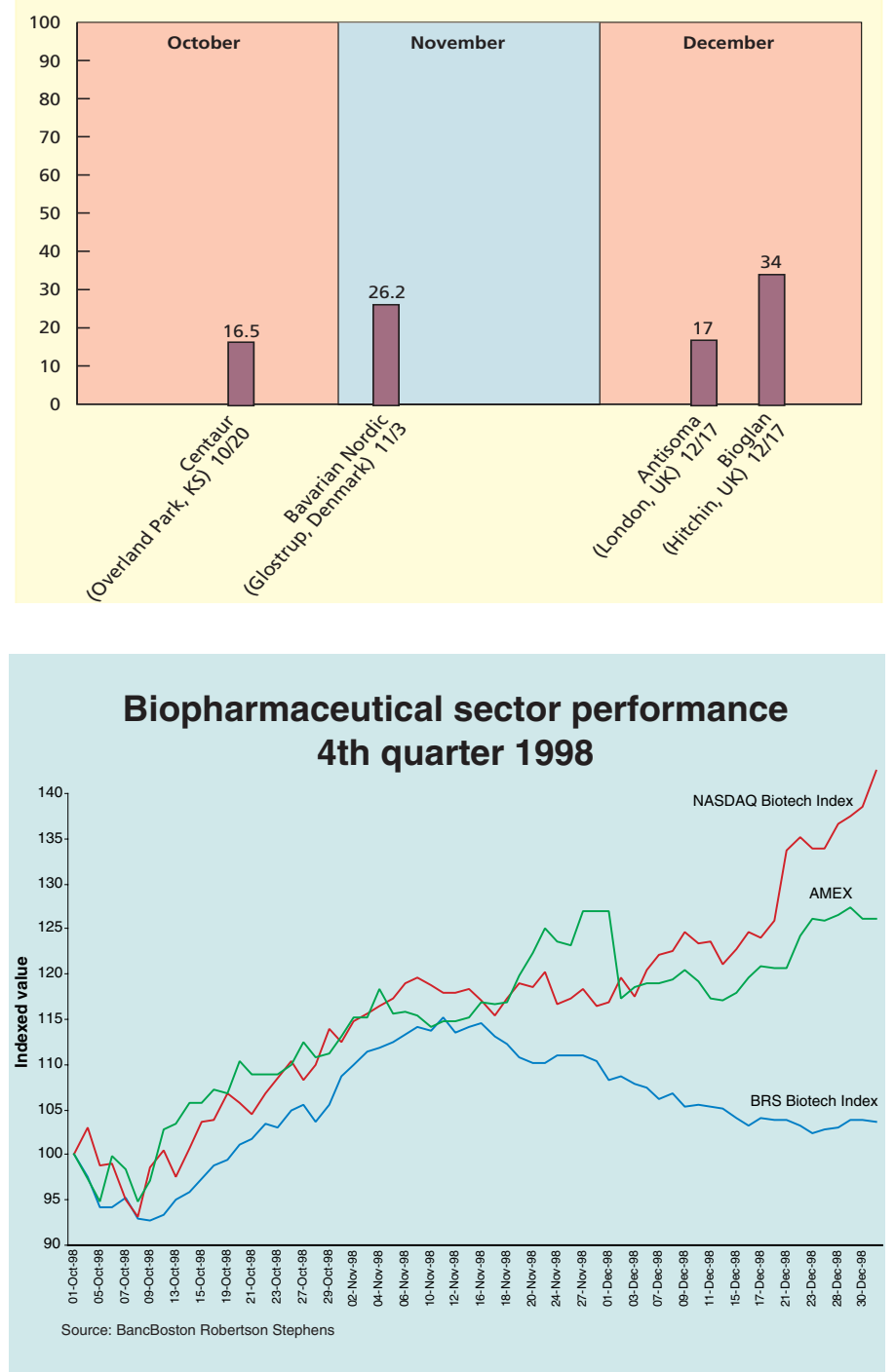

\section{UK news is good and bad}

The first drug from a UK biotechnology company to be approved on both sides of the Atlantic could face a bumpy ride to market thanks to the merger of Astra (Stockholm) with Zeneca (London) (Nat. Biotechnol. 17:7). Chiroscience's (Cambridge, UK) Chirocaine, a chirally pure version of the long-lasting local anesthetic bupivacaine was set to be globally commercialized (except in Japan) following a March 1998 licensing agreement with Zeneca. However, Astra owns the main competitor, Marcaine (also based on bupivacaine), and anticompetition laws require another company to sell one of the products, according to Chiroscience CEO John Padfield. Initially, Chirocaine looked to be the more desirable product to retain because Marcaine, unlike its competitor, comes with a warning that certain doses should not be used in obstetrics patients. However, during the FDA approval review of Chirocaine, the FDA decided that, on presentation of more data, the warning could be removed from Marcaine, putting it on equal footing with Chirocaine. But Padfield is optimistic that Chirocaine will reach the market before Marcaine's warning is removed. In any event, offers to purchase Chirocaine are rolling in, he says. "We are in a win-win situation."

\section{Flu deal is nothing to sneeze at}

Last month, Aviron (Mountain View, CA) announced an agreement with Wyeth Lederle Vaccines (St. Davids, PA), a subsidiary of American Home Products (Madison, NJ), to market Aviron's intranasal influenza vaccine, FluMist. Under the deal, which could total $\$ 400$ million and last up to 11 years, Aviron and Wyeth Lederle will copromote FluMist in the US, but Wyeth has the rights to independently market the product elsewhere (except in areas where previously licensed). In return, Aviron will receive license fees, milestone payments, research funding, and royalties. The money will be used to fund Aviron's business and develop its corporate infrastructure, says Carol Olson, Aviron's senior vice president of commercial development, so that at the end of the agreement, when the product rights revert back to Aviron, the company will be able to sell and promote the product on its own. "This agreement certainly gives us a lot of flexibility to determine what we will do [with our future products]," she adds.

\section{Biotechnology fundraising, Q4 1998 v. Q3 1998}

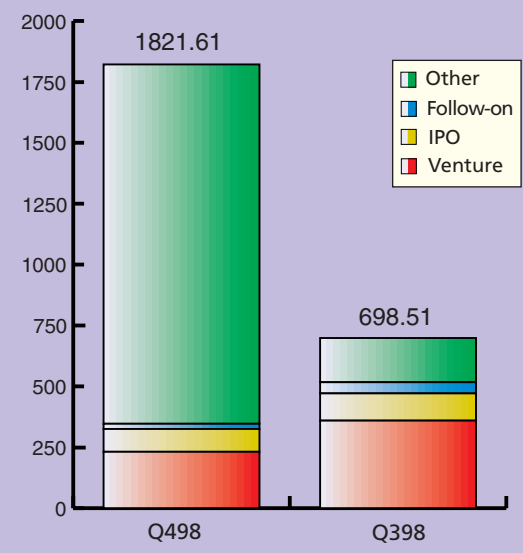

Value in US\$million. Source: BioCentury

\section{A rotten year for funding}

Biotechnology companies raised $44 \%$ less money in 1998 than in 1997, according to a report from the private merchant bank Burrill \& Co. (San Francisco, CA). At the close of 1998, only $\$ 4$ billion had been raised, compared to $\$ 7.1$ billion the year before. Additionally, there were only 14 initial public offerings in 1998 (raising \$371 million) compared with 27 in 1997, which raised $\$ 709$ million. The report blames the poor capital markets in the last half of 1998 for the collapse in funding, and predicts a gloomy 1999 for small biotechnology companies without product revenues, as investors turn to lower risk enterprises, such as those linked to the Internet.

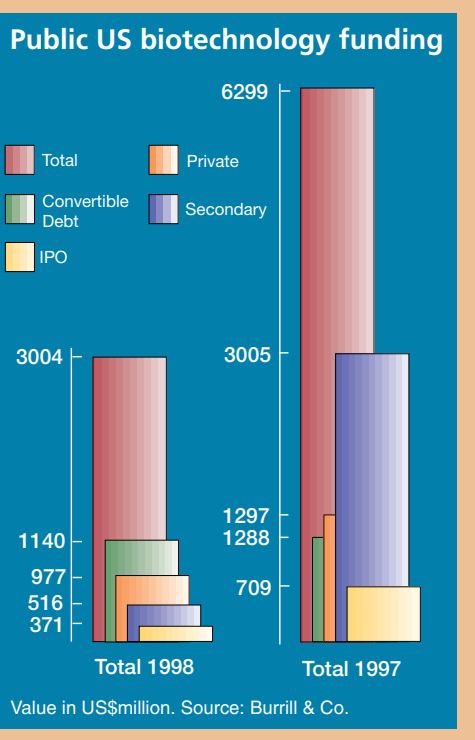

